\title{
A recombinant BCG-based vaccine against the human respiratory syncytial virus induces a balanced cellular immune response against viral and mycobacterial antigens
}

\author{
Gaspar A. Pacheco ${ }^{1}$, Nicolás M. S. Gálvez ${ }^{1}$, Catalina A. Andrade ${ }^{1}$, Yaneisi Vázquez ${ }^{1}$, Linmar Rodríguez- \\ Guilarte $^{1}$, Pablo A. González ${ }^{1}$, Susan M. Bueno ${ }^{1}$, Alexis M. Kalergis ${ }^{1,2^{*}}$ \\ ${ }^{1}$ Millennium Institute of Immunology and Immunotherapy, Departamento de Genética Molecular y Microbiología, \\ Facultad de Ciencias Biológicas, Pontificia Universidad Católica de Chile, Santiago, Chile. ${ }^{2}$ Departamento de \\ Endocrinología, Facultad de Medicina, Pontificia Universidad Católica de Chile, Santiago, Chile \\ *Corresponding author: Dr. Alexis M. Kalergis. Full Professor and Director, Millennium Institute of Immunology \\ and Immunotherapy, Pontificia Universidad Católica de Chile. Av. Libertador Bernardo O’Higgins 340. Email: \\ akalergis@bio.puc.cl
}

Keywords: hRSV, vaccine, BCG, clinical trial, cellular response.

\begin{abstract}
BACKGROUND: The human respiratory syncytial virus (hRSV) is a respiratory pathogen responsible for most cases of acute lower respiratory tract infections in infants worldwide. Although this virus represents a significant social and economic burden, there are no safe and effective available vaccines. rBCG-N-hRSV is a vaccine candidate consisting of a recombinant attenuated Mycobacterium bovis Bacillus Calmette-Guérin (BCG) expressing the nucleoprotein of hRSV (N-hRSV).
\end{abstract}

METHODS: rBCG-N-hRSV was applied intradermally in three different doses $\left(5 \times 10^{3}, 5 \times 10^{4}\right.$, or $1 \times 10^{5} \mathrm{CFU}$ ) to healthy adults enrolled in a randomized, double-blind, dose-escalating phase 1 clinical trial (NCT03213405). Blood samples were taken before and at various time points after immunization. Cellular and humoral immune parameters were assessed by analyzing circulating immune cells and sera, respectively.

RESULTS: Perforin- and Granzyme B-producing PBMCs recognizing viral or mycobacterial antigens were found to increase after immunization with rBCG-N-hRSV. These cells also upregulated IFN- $\gamma$ and IL-10 secretion in response to N-hRSV and upregulated IFN- $\gamma$, IL-6, and 
TNF- $\alpha$ secretion in response to mycobacterial proteins. While naïve $\mathrm{T}$ cell populations contracted over time, no specific memory T cell subset expanded significantly. Although binding to $\mathrm{Clq}$ by anti-N-hRSV or anti-mycobacterial antibodies decreased slightly after immunization, no apparent changes were found in the concentration of IgG subclasses against N-hRSV or mycobacterial antigens.

CONCLUSIONS: The immune response elicited by immunization with rBCG-N-hRSV consists mainly of antigen-specific $\mathrm{T}$ cells. The data reported here provide novel information about the characteristics of the immune response elicited after immunization with rBCG-N-hRSV, supporting the safety and immunogenicity of this vaccine. 
medRxiv preprint doi: https://doi.org/10.1101/2022.02.07.22270648; this version posted February 9, 2022. The copyright holder for this preprint (which was not certified by peer review) is the author/funder, who has granted medRxiv a license to display the preprint in perpetuity. It is made available under a CC-BY-NC-ND 4.0 International license .

\section{INTRODUCTION}

The human respiratory syncytial virus (hRSV) is the leading etiological agent for acute lower respiratory tract infections (ALRTISs) in children under 5 years old, the elderly, and immunocompromised patients [1]. This virus is responsible for over 30 million hospitalizations and over 200,000 deaths per year worldwide [1], [2]. Typical symptoms of ALRTIs include nasal congestion, fever, wheezing, bronchoconstriction, bronchial and alveolar collapse due to excessive mucus production, and pneumonia [3]. However, symptoms associated with hRSV infection may reach far beyond acute disease, as infection with hRSV may lead to sequelae, such as the development of asthma later in life and neurological and cognitive impairment [4]-[6]. Despite the substantial social and economic burden that hRSV poses, there are no safe and effective vaccines against this virus approved to date. One of the current vaccine candidates against hRSV is rBCG-N-hRSV, a vaccine based on an attenuated Mycobacterium bovis Bacillus Calmette-Guérin (BCG) that recombinantly expresses the nucleoprotein of hRSV (N-hRSV) [7][11]. The design of this vaccine is highly advantageous as BCG is one of the oldest and safest vaccines used to date and is currently applied to newborns to prevent tuberculosis in most countries [12], [13]. Thus, this BCG strain could potentially grant protection against both tuberculosis and hRSV in newborns, which represent the most at-risk population of hRSVcaused ALRTIs. rBCG-N-hRSV has been thoroughly tested in animal models and has shown to induce protective humoral and cellular immunity against hRSV after viral challenge in both, mice and calves [8]-[11]. Importantly, a randomized, double-blind, dose-escalating phase 1 clinical trial was carried out to evaluate the safety, tolerability, and transmissibility of this live attenuated vaccine candidate in healthy male adults [7]. The vaccine was found to be safe and well-tolerated in adults at all tested doses, and no evidence of transmissibility of this BCG strain was found. Moreover, preliminary immunogenicity data were generated, finding that rBCG-NhRSV induces a cellular immune response characterized by enhanced IFN- $\gamma$ and IL-2 secretion after stimulation with either N-hRSV or mycobacterial antigens, especially at the higher doses tested [7]. The primary cell type associated with the secretion of these cytokines was presumed to be $\mathrm{CD}^{+}$helper $\mathrm{T}$ cells. Total IgG against N-hRSV or mycobacterial antigens were not found to be statistically increased after immunization. Here, we provide new data and a more in-depth characterization of the cellular and humoral immune response elicited by immunization with the rBCG-N-hRSV vaccine. 
medRxiv preprint doi: https://doi.org/10.1101/2022.02.07.22270648; this version posted February 9, 2022. The copyright holder for this preprint (which was not certified by peer review) is the author/funder, who has granted medRxiv a license to display the preprint in perpetuity. It is made available under a CC-BY-NC-ND 4.0 International license .

\section{METHODS}

\section{Phase 1 Clinical Trial study design and sample collection}

A randomized, double-blind, dose-escalating Phase 1 Clinical Trial was carried out (NCT03213405), which primary and secondary outcomes evaluated were safety, tolerability, transmissibility, and immunogenicity of the rBCG-N-hRSV vaccine in healthy adults [7]. The study protocol followed current ethical guidelines, such as Tripartite Guidelines for Good Clinical Practices, the Declaration of Helsinki [14], and local regulations. This study was approved by both, the Institutional Ethical Committee (number 15216) and the Institute of Public Health of Chile (ISP Chile, number EC819077/16). Inclusion and exclusion criteria and additional information about this clinical trial was reported previously [7]. Briefly, 24 male adults aged 18-50 years were enrolled and randomized into three cohorts consisting of eight subjects each. Two participants were immunized intradermally in the deltoid area with $2 \times 10^{5}$ CFU of BCG-WT in each cohort [7]. The remaining six subjects were vaccinated with escalating doses of rBCG-N-hRSV $\left(5 \times 10^{3}, 5 \times 10^{4}\right.$, or $1 \times 10^{5}$ CFU) [7]. Data obtained from subjects immunized with BCG-WT were analyzed together, independently of their cohort [7]. Blood samples were taken before immunization (Day 0) and 14, 30, 60, 120, and 180 days postimmunization [7]. Peripheral blood mononuclear cells (PBMCs) and sera were isolated from these blood samples and stored in liquid nitrogen and in a $-80^{\circ} \mathrm{C}$ freezer, respectively.

\section{Perforin/Granzyme B ELISPOT Assays}

The secretion of Perforin (Perf) and Granzyme B (GrzB) by PBMCs was evaluated using the Human Granzyme B/Perforin Double-Color Enzymatic ELISPOT Assay (ImmunoSpot). The assay was performed according to the manufacturer instructions, incubating the cells with each stimulus for 48 hours at $37^{\circ} \mathrm{C}$ and $5 \% \mathrm{CO}_{2} .2 \times 10^{5} \mathrm{PBMCs}$ were plated and stimulated with either $1.25 \mu \mathrm{g} / \mathrm{mL}$ N-hRSV (Genscript) or $750 \mathrm{IU} / \mathrm{mL}$ bovine PPD (ThermoScientific). Positive and negative stimulation controls were also included as internal controls (data not shown). After developing the plates, these were air-dried face-down on a paper towel for $24 \mathrm{~h}$, and then stored with the underdrain on until spots were counted with an ImmunoSpot S6 CORE Analyzer (Immunospot). 
medRxiv preprint doi: https://doi.org/10.1101/2022.02.07.22270648; this version posted February 9, 2022. The copyright holder for this preprint (which was not certified by peer review) is the author/funder, who has granted medRxiv a license to display the preprint in perpetuity. It is made available under a CC-BY-NC-ND 4.0 International license .

\section{Serum cytokine measurements by Cytometric Bead Array ${ }^{\mathrm{TM}}$}

Cytokine measurements were performed using the $\mathrm{BD}^{\mathrm{TM}}$ Cytometric Bead Array (CBA) Human Th1/Th2/Th17 Cytokine Kit (BD Biosciences). Determinations were performed following the manufacturer instructions, with either undiluted sera or culture supernatant of PBMCs diluted 1:4. The median fluorescent intensity of PE fluorochrome (MeFI) in each bead population was calculated for every sample. A 4-parameter logistic (4PL) standard curve was constructed using PE MeFI for each cytokine, subtracting the signal from the blank tube to each sample and standard. Cytokine concentrations were obtained from the respective standard curve.

\section{Memory $\mathbf{T}$ cell quantification by flow cytometry}

PBMCs stored in liquid nitrogen were thawed, stimulated with the indicated antigens, and analyzed as previously described [7]. Briefly, cells were pelleted, resuspended, and stimulated with $2.5 \mu \mathrm{g} / \mathrm{mL} \mathrm{N}$-hRSV or $25 \mu \mathrm{g} / \mathrm{mL}$ PPD for 5 hours and then incubated for 16 hours with a cocktail of secretion inhibitors [7]. Staining was performed as previously described [7] and data were acquired in a BD LSRFortessa $\mathrm{X}-20^{\mathrm{TM}}$. Gating and analyses were performed using the FlowJo software (V10.6.2).

\section{C1q-binding assays}

C1q binding to antibodies was measured by ELISA on plates coated O.N. at $4^{\circ} \mathrm{C}$ with $50 \mu \mathrm{L}$ of either $1 \mu \mathrm{g} / \mathrm{mL} \mathrm{N}$-hRSV (Genscript) or $25 \mu \mathrm{g} / \mathrm{mL}$ bovine PPD (ThermoScientific) in $100 \mathrm{mM}$ bicarbonate/carbonate $\mathrm{pH} 9.5$ buffer. Then, plates were washed three times with PBS-Tween 20 $0.05 \%$ (Wash buffer) and then blocked for two hours with $200 \mu \mathrm{L}$ of PBS-Milk 5\% (Blocking solution). Sera samples were diluted 1:30 in blocking solution and inactivated at $56^{\circ} \mathrm{C}$ for 30 minutes. Plates were washed three times, incubated with $50 \mu \mathrm{L}$ of inactivated sera samples for one hour at RT, washed three times, incubated for one hour with $50 \mu \mathrm{L}$ of $4 \mu \mathrm{g} / \mathrm{mL}$ purified human $\mathrm{C} 1 \mathrm{q}$ diluted in blocking solution, washed five times, incubated for one hour with $50 \mu \mathrm{L}$ of mouse anti-human C1q (Invitrogen) diluted 1:2,000, washed seven times, incubated for two hours with $50 \mu \mathrm{L}$ of rat anti-mouse IgG1-HRP (Invitrogen) diluted 1:2,000, washed seven times with $200 \mu \mathrm{L}$ of wash buffer and then washed manually one time with $200 \mu \mathrm{L}$ of PBS. $50 \mu \mathrm{L}$ of TMB (ThermoScientific) were added and incubated for 15 minutes at RT. Then, $50 \mu \mathrm{L}$ of $2 \mathrm{~N}$ 
medRxiv preprint doi: https://doi.org/10.1101/2022.02.07.22270648; this version posted February 9, 2022. The copyright holder for this preprint (which was not certified by peer review) is the author/funder, who has granted medRxiv a license to display the preprint in perpetuity.

It is made available under a CC-BY-NC-ND 4.0 International license .

sulfuric acid were added and the absorbance at $450 \mathrm{~nm}$ was immediately measured. A C1q standard curve was incorporated in every plate. A C1q Binding Index was defined and calculated as follows:

C1q Binding Index = Bound C1q (ng) $/ \log _{10}($ Antibody Concentration $[\mathrm{ng} / \mathrm{mL}])$

\section{IgG subclass quantification by ELISA}

ELISA plates were coated O.N. at $4^{\circ} \mathrm{C}$ with $50 \mu \mathrm{L}$ of $2 \mu \mathrm{g} / \mathrm{mL}$ N-hRSV (Genscript) or $25 \mu \mathrm{g} / \mathrm{mL}$ bovine PPD (ThermoScientific) in sodium carbonate/bicarbonate $100 \mathrm{mM} \mathrm{pH} 9.5$ buffer. Then, plates were washed three times with $200 \mu \mathrm{L}$ of PBS-Tween $200.05 \%$ (Wash buffer). Plates were blocked with PBS-FBS 10\% (Blocking solution) for two hours at RT, washed three times, incubated with sera diluted 1:5 in blocking solution for two hours, washed three times, incubated for one hour with $50 \mu \mathrm{L}$ of either rat anti-human IgG1 (BioLegend) or rat anti-human IgG2 (BioLegend) diluted 1:500, washed three times, incubated for one hour with $50 \mu \mathrm{L}$ of rat antimouse IgG1-HRP (Invitrogen) diluted 1:2,000, washed three times with $200 \mu \mathrm{L}$ of wash buffer and manually washed one time with $200 \mu \mathrm{L}$ of PBS. $50 \mu \mathrm{L}$ of TMB Substrate Reagent (ThermoScientific) were added to each well. $50 \mu \mathrm{L}$ of $2 \mathrm{~N}$ sulfuric acid were added to each well and absorbance at $450 \mathrm{~nm}$ was immediately measured. Standard curves for IgG1 or IgG2 were incorporated in every plate.

\section{Statistical analyses}

All graphics and statistical analyses were performed in GraphPad Prism, version 9.1.0. Analyses of the standard curves obtained in ELISA assays were performed by an unconstrained 4parameter logistic regression (4PL). Data were then interpolated in those regressions. To calculate fold-changes relative to pre-immune conditions, the observed response variable at a given time was divided by that observed at Day 0. A two-way ANOVA for repeated measures with post-hoc Dunnet's test corrected for multiple comparisons against Day 0 was performed to evaluate differences after immunization. Base 10 logarithms of fold changes were calculated before statistical analyses. 
medRxiv preprint doi: https://doi.org/10.1101/2022.02.07.22270648; this version posted February 9, 2022. The copyright holder for this preprint (which was not certified by peer review) is the author/funder, who has granted medRxiv a license to display the preprint in perpetuity.

It is made available under a CC-BY-NC-ND 4.0 International license .

\section{RESULTS}

\section{A single dose of rBCG-N-hRSV induces moderate inflammation in healthy adults}

The safety and reactogenicity of three escalating doses of rBCG-N-hRSV had been studied previously [7]. However, molecular immune parameters that support that this vaccine does not induce systemic hyper-inflammation had not been measured. Thus, we evaluated the concentration of various cytokines in sera of immunized subjects. Cytokine concentrations was determined at days $0,14,30,60,120$, and 180 post-immunization for subjects immunized either with one of the three doses tested of rBCG-N-hRSV, or a standard dose of BCG-WT (Fig. 1 and Supp. Fig. 1). Cytokine responses were heterogenous among subjects within the same group (Fig. 1). Nonetheless, all cytokines were found in very low concentrations in the sera, consistent with the lack of an exacerbated inflammation after immunization. Only a slight induction of early IFN- $\gamma$ was observed in sera from subjects immunized with the highest doses tested for the vaccine (Fig. 1A). These results suggest that the application of rBCG-N-hRSV does not induce systemic hyper-inflammation, which further supports the safety of this vaccine candidate in healthy adults.

\section{rBCG-N-hRSV primes hRSV- and mycobacterial-specific cytotoxic $T$ cells in healthy adults}

One of the advantages of the rBCG-N-hRSV vaccine is the possibility to simultaneously induce, anti-mycobacterial and antiviral immune responses [8]. While the $\mathrm{CD} 4^{+}$helper $\mathrm{T}$ cell responses against N-hRSV and mycobacterial antigens after rBCG-N-hRSV immunization have already been evaluated [7], the secretion of cytotoxic molecules by $\mathrm{CD}^{+}$cytotoxic $\mathrm{T}$ cells against these antigens had not been previously assessed. The number of $\mathrm{Perf}^{+}$and $\mathrm{GrzB}^{+}$spot-forming cells (SFCs) was counted for each of the PBMCs samples obtained from immunized subjects upon in vitro stimulation for $48 \mathrm{~h}$ with either N-hRSV (Fig. 2A-C) or PPD (Fig. 2D-F). Double positive $\left(\right.$ Perf $^{+} \mathrm{GrzB}^{+}$) SFCs were also measured (Supp. Fig 2), as well as the fold-changes relative to the pre-immune condition (Supp. Fig 3). The stimulation of PBMCs with N-hRSV induced a potent effector cytotoxic molecule response only in subjects immunized with $5 \times 10^{4}$ CFU of rBCG-NhRSV (Fig. 2A-C \& Supp. Fig. 3A-C). A strong Perforin response was observed in PBMCs from subjects of this cohort (Figure 2B \& Supp. Fig. 3A), which showed a progressive increase

in Perforin secretion up to day 60 post-immunization. Granzyme B responses were modest and 
medRxiv preprint doi: https://doi.org/10.1101/2022.02.07.22270648; this version posted February 9, 2022. The copyright holder for this preprint (which was not certified by peer review) is the author/funder, who has granted medRxiv a license to display the preprint in perpetuity. It is made available under a CC-BY-NC-ND 4.0 International license .

only slightly increased for these subjects (Fig. 2C \& Supp. Fig. 3B). PBMCs obtained from individuals immunized with BCG-WT and stimulated with N-hRSV did not produce the evaluated cytotoxic molecules, which was expected. Importantly, the stimulation of PBMCs with PPD (a purified protein fraction of tuberculin) induced an effector cytotoxic response based on molecular markers in subjects immunized with either $2 \times 10^{5} \mathrm{CFU}$ of BCG-WT or $5 \times 10^{4} \mathrm{CFU}$ of rBCG-N-hRSV (Fig. 2D-F). As expected, subjects vaccinated with BCG-WT showed a progressive increase in responsiveness against PPD after immunization (Fig. 2E-F). Our results suggest that $5 \times 10^{4} \mathrm{CFU}$ of $\mathrm{rBCG}-\mathrm{N}-\mathrm{hRSV}$ is the optimal dose to induce the secretion of cytotoxic molecules by PBMCs in response to either PPD or N-hRSV (Fig. 2). Accordingly, the secretion of Perforin and Granzyme B in response to stimulation with N-hRSV is dependent on the expression of N-hRSV by the BCG vaccine. Given that we observed an antigen-specific T cell response in subjects immunized with rBCG-N-hRSV, we sought to determine whether immunization alone could promote the expansion of memory $\mathrm{T}$ cell subsets [15] (gating shown in Supp. Fig. 4). Stimulation of PBMCs with N-hRSV or PPD led to an apparent contraction for both the naïve $\mathrm{CD}^{+}$and $\mathrm{CD}^{+} \mathrm{T}$ cell populations (Figs. $3 \&$ 4). However, neither central memory $\mathrm{T}$ cells $\left(\mathrm{T}_{\mathrm{CM}}\right)$, effector memory $\mathrm{T}$ cells $\left(\mathrm{T}_{\mathrm{EM}}\right)$, nor CD45RA-expressing effector memory $\mathrm{T}$ cells $\left(\mathrm{T}_{\mathrm{EMRA}}\right)$ seemed to expand to a significant extent after one single dose of rBCG-N-hRSV (Figs. 3 \& 4).

\section{PBMCs derived from rBCG-N-hRSV-vaccinated subjects produce cytokines in response to N-hRSV and mycobacterial antigens}

Secretion of pro- and anti-inflammatory cytokines by PBMCs derived from rBCG-N-hRSVvaccinated subjects in response to in vitro stimulation with N-hRSV (Fig. 5) or PPD (Fig. 6) was measured. Stimulation of PBMCs with N-hRSV led to increased levels of IFN- $\gamma$ and IL-10 after immunization (Fig. 5 and Supp. Fig. 5). Interestingly, the ratios of IL-6/IFN- $\gamma$ and TNF- $\alpha /$ IFN- $\gamma$ decreased in subjects immunized with $5 \times 10^{3}$ or $5 \times 10^{4}$ CFU of rBCG-N-hRSV (Fig. 5G \& H). On the other hand, stimulation of PBMCs with PPD led to increased levels of IFN- $\gamma$, TNF- $\alpha$, IL2, and IL-6 (Fig. 6 and Supp. Fig. 6) in subjects immunized with $5 \times 10^{3}$ or $5 \times 10^{4}$ CFU of rBCGN-hRSV. Subjects immunized with $5 \times 10^{5}$ CFU of BCG-WT also showed an upregulation of IL6 , as well as moderate IFN- $\gamma$, TNF- $\alpha$, and IL-2 responses. A minor IL-10 response was detected for PBMCs from subjects immunized with $5 \times 10^{4} \mathrm{CFU}$ of rBCG-N-hRSV. These results suggest 
medRxiv preprint doi: https://doi.org/10.1101/2022.02.07.22270648; this version posted February 9, 2022. The copyright holder for this preprint (which was not certified by peer review) is the author/funder, who has granted medRxiv a license to display the preprint in perpetuity.

It is made available under a CC-BY-NC-ND 4.0 International license .

that immunization with either $5 \times 10^{3}$ or $5 \times 10^{4}$ CFU of rBCG-N-hRSV led to the secretion of proinflammatory cytokines typically associated with immune responses against intracellular pathogens, such as viruses and mycobacteria [16]-[19]. Moreover, the modest increase in IL-10 concentration is indicative of a balanced immune response [20].

\section{Reduced C1q binding by virus- and mycobacteria-specific antibodies induced by rBCG-N- hRSV}

While it had been previously reported that the concentration of anti-N-hRSV antibodies in sera do not significantly change after immunization with rBCG-N-hRSV [7], it is possible that immunization with rBCG-N-hRSV may change the relative proportions of anti-N-hRSV IgG subclasses. Thus, the ability of anti-N-hRSV antibodies to bind exogenous C1q efficiently was measured as a functional assay for relative subclass composition of anti-N-hRSV IgG [21]. Exogenous C1q binding to anti-N-hRSV or anti-PPD antibodies in the sera was quantified for each sample (Fig. 7A-B). Both, anti-N-hRSV and anti-PPD antibodies from subjects immunized with $5 \times 10^{4} \mathrm{CFU}$ of rBCG-N-hRSV were found to bind less complement after immunization, as compared to the other groups (Fig. 7A-B). Importantly, these tendencies were maintained when C1q binding was normalized by total anti-N or anti-PPD IgG titers (C1q Binding Index) (Fig. 7C-D). Analyses of fold changes compared to the pre-immune condition showed similar results (Supp. Fig. 7).

\section{rBCG-N-hRSV immunization induces equivalent IgG subclass secretion}

The concentration of anti-N-hRSV and anti-PPD IgG1 and IgG2 in the sera of immunized subjects were quantified by ELISA. Immunization with rBCG-N-hRSV did not appear to change the concentration of these IgG subclasses, neither for anti-N-hRSV nor for anti-PPD antibodies (Fig. 8). As expected, IgG1 titers for anti-N-hRSV were higher than IgG2 titers (Fig. 8A \& C). Surprisingly, IgG2 titers were higher than IgG1 titers for anti-PPD antibodies (Fig. 8B \& D). Analyses of fold changes relative to the pre-immune condition showed similar results (Supp. Fig. 8). 
medRxiv preprint doi: https://doi.org/10.1101/2022.02.07.22270648; this version posted February 9, 2022. The copyright holder for this preprint (which was not certified by peer review) is the author/funder, who has granted medRxiv a license to display the preprint in perpetuity.

It is made available under a CC-BY-NC-ND 4.0 International license .

\section{DISCUSSION}

The results reported herein regarding cytokine concentrations in the sera constitute a good immunological indicator for the safety of rBCG-N-hRSV, given the moderate levels of circuliting cytokines detected (Fig. 1). A slight tendency of increased IFN- $\gamma$ was observed for all experimental groups, except for those subjects immunized with the lowest dose of rBCG-NhRSV. The increase in IFN- $\gamma$ concentration can be interpreted as a positive result because this cytokine can be beneficial against hRSV [22]-[24]. This response is short-lived, may be dosedependent [12], [13], [25] and is consistent with the notion that BCG can induce $\mathrm{T}_{\mathrm{H}} 1$ responses in humans [26]-[28], which is one of the reasons as to why it was selected as a vector for immunizing against hRSV antigens [7]-[11], [13], [29], [30].

Furthermore, rBCG-N-hRSV had previously been shown to be an efficient inducer of $\mathrm{T}_{\mathrm{H}} 1$ cellular responses against N-hRSV in healthy adults in this clinical trial, as measured by the secretion of IFN- $\gamma$ by PBMCs [7]. Our results further support this notion since subjects immunized with $5 \times 10^{4} \mathrm{CFU}$ of rBCG-N-hRSV showed a considerable Perforin and Granzyme B response against PPD and N-hRSV (Fig. 2), as well as by the increase in IFN- $\gamma$ concentration in cultures of stimulated PBMCs (Figs. 5 \& 6). The heterogenous secretion of cytotoxic molecules shown by PBMCs from subjects immunized with different doses of rBCG-N-hRSV in response to N-hRSV could be explained by differential exposure to community hRSV during seasonal outbreaks by this virus.

Even though we detected no expansion of memory $\mathrm{T}$ cells in response to immunization with either BCG-WT or rBCG-N-hRSV alone (Figs. 3 \& 4), natural infection with hRSV after immunization with rBCG-N-hRSV could enhance the expansion of memory $\mathrm{T}$ cell subsets, as seen for other viruses [31], [32]. However, this remains to be determined, as none of the study subjects reported hRSV-associated symptoms during the study.

Lastly, decreased complement binding via the classical pathway was observed after immunization with rBCG-N-hRSV, especially at the higher doses (Fig. 7). However, no detectable changes in IgG1 or IgG2 concentrations were found for antibodies specific against $\mathrm{N}$ hRSV or PPD (Fig. 8). The relevance of this subtle change in antibody effector function remains to be determined, but it seems a good indicator of the safety for this vaccine candidate [33]. 
Limitations of this study include the low sample size, considering that the primary outcome of the clinical trial was to evaluate safety for this recombinant BCG vaccine. Moreover, the immune response evaluated herein was assessed only during an immune steady state, so differential immune responses after infection are yet to be determined. Lastly, while assessing the immune response elicited by $\mathrm{rBCG}-\mathrm{N}-\mathrm{hRSV}$ in healthy male adults was necessary before evaluating this vaccine in the pediatric population, the response elicited in newborns and infants would be particularly relevant, considering that they are the target population for immunization against hRSV. Our data support the immunological safety and appropriateness of rBCG-N-hRSV as a vaccine against this viral pathogen, upon further clinical efficacy evaluation. 


\section{AUTHOR CONTRIBUTIONS}

Conceptualization: G.A.P., N.M.S.G., C.A.A., P.A.G., S.M.B., A.M.K.

Visualization: G.A.P., N.M.S.G., C.A.A., P.A.G., S.M.B., A.M.K.

Methodology: G.A.P., N.M.S.G., C.A.A., L.R-G., Y.V.

Investigation: G.A.P., N.M.S.G., C.A.A., L.R-G., Y.V., P.A.G., S.M.B., A.M.K.

Funding acquisition: P.A.G., S.M.B., A.M.K.

Project administration: P.A.G., S.M.B., A.M.K.

Supervision: P.A.G., S.M.B., A.M.K.

Writing - original draft: G.A.P., A.M.K.

Writing - Review and editing: G.A.P., N.M.S.G., C.A.A., L.R-G., Y.V., P.A.G., S.M.B., A.M.K.

\section{FUNDING}

This work was supported by the Agencia Nacional de Investigación y Desarrollo [FONDECYT grant numbers 1190830 to A.K., 21190183 to N.M.S.G., and 21210662 to C.A.P.] and by the Millenium Institute on Immunology and Immunotherapy [ANID-Millenium Science Initiative Program ICN09_016 (former P09/016F)].

\section{POTENTIAL CONFLICTS OF INTEREST}

P.A.G., S.M.B., and A.M.K. hold a patent for the rBCG-N-hRSV vaccine with Pontificia Universidad Católica de Chile (PCT/US2008/076682). 
medRxiv preprint doi: https://doi.org/10.1101/2022.02.07.22270648; this version posted February 9, 2022. The copyright holder for this preprint (which was not certified by peer review) is the author/funder, who has granted medRxiv a license to display the preprint in perpetuity.

\section{REFERENCES}

[1] H. Nair, D. J. Nokes, B. D. Gessner, et al., "Global burden of acute lower respiratory infections due to respiratory syncytial virus in young children: a systematic review and meta-analysis," The Lancet, 2010, doi: 10.1016/S0140-6736(10)60206-1.

[2] L. Bont, P. A. Checchia, B. Fauroux, et al., "Defining the Epidemiology and Burden of Severe Respiratory Syncytial Virus Infection Among Infants and Children in Western Countries," Infectious Diseases and Therapy. 2016, doi: 10.1007/s40121-016-0123-0.

[3] J. S. Tregoning and J. Schwarze, "Respiratory viral infections in infants: Causes, clinical symptoms, virology, and immunology," Clinical Microbiology Reviews, vol. 23, no. 1. pp. 74-98, 2010, doi: 10.1128/CMR.00032-09.

[4] K. Bendelja, A. Gagro, A. Bace, et al., "Predominant type-2 response in infants with respiratory syncytial virus (RSV) infection demonstrated by cytokine flow cytometry," Clinical and Experimental Immunology, vol. 121, no. 2, pp. 332-338, 2000, doi: 10.1046/j.1365-2249.2000.01297.x.

[5] T. Jartti and J. E. Gern, "Role of viral infections in the development and exacerbation of asthma in children," The Journal of allergy and clinical immunology, vol. 140, no. 4, pp. 895-906, Oct. 2017, doi: 10.1016/j.jaci.2017.08.003.

[6] J. A. Espinoza, K. Bohmwald, P. F. Cespedes, et al., "Impaired learning resulting from respiratory syncytial virus infection," Proc Natl Acad Sci U S A, vol. 110, no. 22, pp. 9112-9117, 2013, doi: 10.1073/pnas.1217508110.

[7] K. Abarca, E. Rey-Jurado, N. Muñoz-Durango, et al., "Safety and immunogenicity evaluation of recombinant BCG vaccine against respiratory syncytial virus in a randomized, double-blind, placebo-controlled phase I clinical trial.," EClinicalMedicine, vol. 27, p. 100517, Oct. 2020, doi: 10.1016/j.eclinm.2020.100517.

[8] P. F. Céspedes, E. Rey-Jurado, J. A. Espinoza, et al., "A single, low dose of a cGMP recombinant $\mathrm{BCG}$ vaccine elicits protective $\mathrm{T}$ cell immunity against the human respiratory syncytial virus infection and prevents lung pathology in mice," Vaccine, vol. 35, no. 5, pp. 757-766, Feb. 2017, doi: 10.1016/j.vaccine.2016.12.048.

[9] F. E. Díaz, M. Guerra-Maupome, P. O. McDonald, et al., "A Recombinant BCG Vaccine Is Safe and Immunogenic in Neonatal Calves and Reduces the Clinical Disease Caused by the Respiratory Syncytial Virus.," Frontiers in immunology, vol. 12, p. 664212, 2021, doi: 10.3389/fimmu.2021.664212.

[10] S. M. Bueno, P. A. González, K. M. Cautivo, et al., "Protective T cell immunity against respiratory syncytial virus is efficiently induced by recombinant BCG," Proceedings of the National Academy of Sciences, vol. 105, no. 52, pp. 20822-20827, 2008, doi: 10.1073/pnas.0806244105. 
medRxiv preprint doi: https://doi.org/10.1101/2022.02.07.22270648; this version posted February 9, 2022. The copyright holder for this preprint (which was not certified by peer review) is the author/funder, who has granted medRxiv a license to display the preprint in perpetuity. It is made available under a CC-BY-NC-ND 4.0 International license .

[11] J. A. Soto, N. M. S. Gálvez, C. A. Rivera, et al., "Recombinant BCG Vaccines Reduce Pneumovirus-Caused Airway Pathology by Inducing Protective Humoral Immunity.," Frontiers in immunology, vol. 9, p. 2875, Dec. 2018, doi: 10.3389/fimmu.2018.02875.

[12] J. A. Soto, N. M. S. Gálvez, C. A. Andrade, et al., "BCG vaccination induces crossprotective immunity against pathogenic microorganisms," Trends in Immunology, 2022, doi: https://doi.org/10.1016/j.it.2021.12.006.

[13] C. Covián, A. Fernández-Fierro, A. Retamal-Díaz, et al., "BCG-Induced Cross-Protection and Development of Trained Immunity: Implication for Vaccine Design.," Frontiers in immunology, vol. 10, p. 2806, 2019, doi: 10.3389/fimmu.2019.02806.

[14] World Medical Association, "World Medical Association Declaration of Helsinki: ethical principles for medical research involving human subjects.," JAMA, vol. 310, no. 20, pp. 2191-4, Nov. 2013, doi: 10.1001/jama.2013.281053.

[15] E. Jimenez Vera, Y. V. Chew, L. Nicholson, et al., "Standardisation of flow cytometry for whole blood immunophenotyping of islet transplant and transplant clinical trial recipients," PLOS ONE, vol. 14, no. 5, p. e0217163, May 2019.

[16] H. C. Bergeron and R. A. Tripp, "Immunopathology of RSV: An Updated Review," Viruses, vol. 13, no. 12, p. 2478, Dec. 2021, doi: 10.3390/v13122478.

[17] S. Ascough, S. Paterson, and C. Chiu, "Induction and subversion of human protective immunity: Contrasting influenza and respiratory syncytial virus," Frontiers in Immunology. 2018, doi: 10.3389/fimmu.2018.00323.

[18] C. B. Korol, S. J. Shallom, K. Arora, et al., "Tissue specific diversification, virulence and immune response to Mycobacterium bovis BCG in a patient with an IFN- $\gamma$ R1 deficiency," Virulence, vol. 11, no. 1, pp. 1656-1673, Dec. 2020, doi: 10.1080/21505594.2020.1848108.

[19] G. Kilinç, A. Saris, T. H. M. Ottenhoff, et al., "Host-directed therapy to combat mycobacterial infections," Immunological reviews, vol. 301, no. 1, pp. 62-83, May 2021, doi: 10.1111/imr.12951.

[20] J. M. Rojas, M. Avia, V. Martín, et al., "IL-10: A Multifunctional Cytokine in Viral Infections," Journal of immunology research, vol. 2017, p. 6104054, 2017, doi: $10.1155 / 2017 / 6104054$.

[21] G. Vidarsson, G. Dekkers, and T. Rispens, "IgG subclasses and allotypes: from structure to effector functions," Frontiers in immunology, vol. 5, p. 520, Oct. 2014, doi: 10.3389/fimmu.2014.00520.

[22] K. M. Eichinger, L. Egaña, J. G. Orend, et al., "Alveolar macrophages support interferon gamma-mediated viral clearance in RSV-infected neonatal mice," Respiratory Research, vol. 16, no. 1, p. 122, Dec. 2015, doi: 10.1186/s12931-015-0282-7. 
medRxiv preprint doi: https://doi.org/10.1101/2022.02.07.22270648; this version posted February 9, 2022. The copyright holder for this preprint (which was not certified by peer review) is the author/funder, who has granted medRxiv a license to display the preprint in perpetuity. It is made available under a CC-BY-NC-ND 4.0 International license .

[23] Y. Ma, Y.-Y. Jiao, Y.-Z. Yu, et al., “A Built-In CpG Adjuvant in RSV F Protein DNA Vaccine Drives a Th1 Polarized and Enhanced Protective Immune Response.," Viruses, vol. 10, no. 1, 2018, doi: 10.3390/v10010038.

[24] S. Boyoglu-Barnum, T. Chirkova, S. O. Todd, et al., "Prophylaxis with a Respiratory Syncytial Virus (RSV) Anti-G Protein Monoclonal Antibody Shifts the Adaptive Immune Response to RSV rA2-line19F Infection from Th2 to Th1 in BALB/c Mice," Journal of Virology, vol. 88, no. 18, pp. 10569-10583, 2014, doi: 10.1128/JVI.01503-14.

[25] J. Leentjens, M. Kox, R. Stokman, et al., "BCG vaccination enhances the immunogenicity of subsequent influenza vaccination in healthy volunteers: A randomized, placebocontrolled pilot study," Journal of Infectious Diseases, vol. 212, no. 12, pp. 1930-1938, 2015, doi: 10.1093/infdis/jiv332.

[26] J. Kleinnijenhuis, J. Quintin, F. Preijers, et al., "Long-lasting effects of BCG vaccination on both heterologous Th1/Th17 responses and innate trained immunity.," Journal of innate immunity, vol. 6, no. 2, pp. 152-8, 2014, doi: 10.1159/000355628.

[27] M. G. Netea and R. van Crevel, "BCG-induced protection: effects on innate immune memory.," Seminars in immunology, vol. 26, no. 6, pp. 512-7, Dec. 2014, doi: 10.1016/j.smim.2014.09.006.

[28] D. Verma, V. R. Parasa, J. Raffetseder, et al., "Anti-mycobacterial activity correlates with altered DNA methylation pattern in immune cells from BCG-vaccinated subjects," Scientific reports, vol. 7, no. 1, Dec. 2017, doi: 10.1038/S41598-017-12110-2.

[29] M. Foster, P. C. Hill, T. P. Setiabudiawan, et al., "BCG-induced protection against Mycobacterium tuberculosis infection: Evidence, mechanisms, and implications for nextgeneration vaccines," Immunological reviews, vol. 301, no. 1, pp. 122-144, May 2021, doi: 10.1111/imr.12965.

[30] E. Rey-Jurado, J. Soto, N. Gálvez, et al., "A safe and efficient BCG vectored vaccine to prevent the disease caused by the human Respiratory Syncytial Virus.," Human vaccines \& immunotherapeutics, vol. 13, no. 9, pp. 2092-2097, Sep. 2017, doi: 10.1080/21645515.2017.1334026.

[31] M. E. Schmidt and S. M. Varga, "The CD8 T cell response to respiratory virus infections," Frontiers in Immunology. 2018, doi: 10.3389/fimmu.2018.00678.

[32] F. Melo-González, J. A. Soto, L. A. González, et al., "Recognition of Variants of Concern by Antibodies and T Cells Induced by a SARS-CoV-2 Inactivated Vaccine," Frontiers in immunology, vol. 12, p. 747830, Nov. 2021, doi: 10.3389/fimmu.2021.747830.

[33] H. W. Kim, J. G. Canchola, C. D. Brandt, et al., "Respiratory syncytial virus disease in infants despite prior administration of antigenic inactivated vaccine," American Journal of Epidemiology, 1969, doi: 10.1093/oxfordjournals.aje.a120955. 

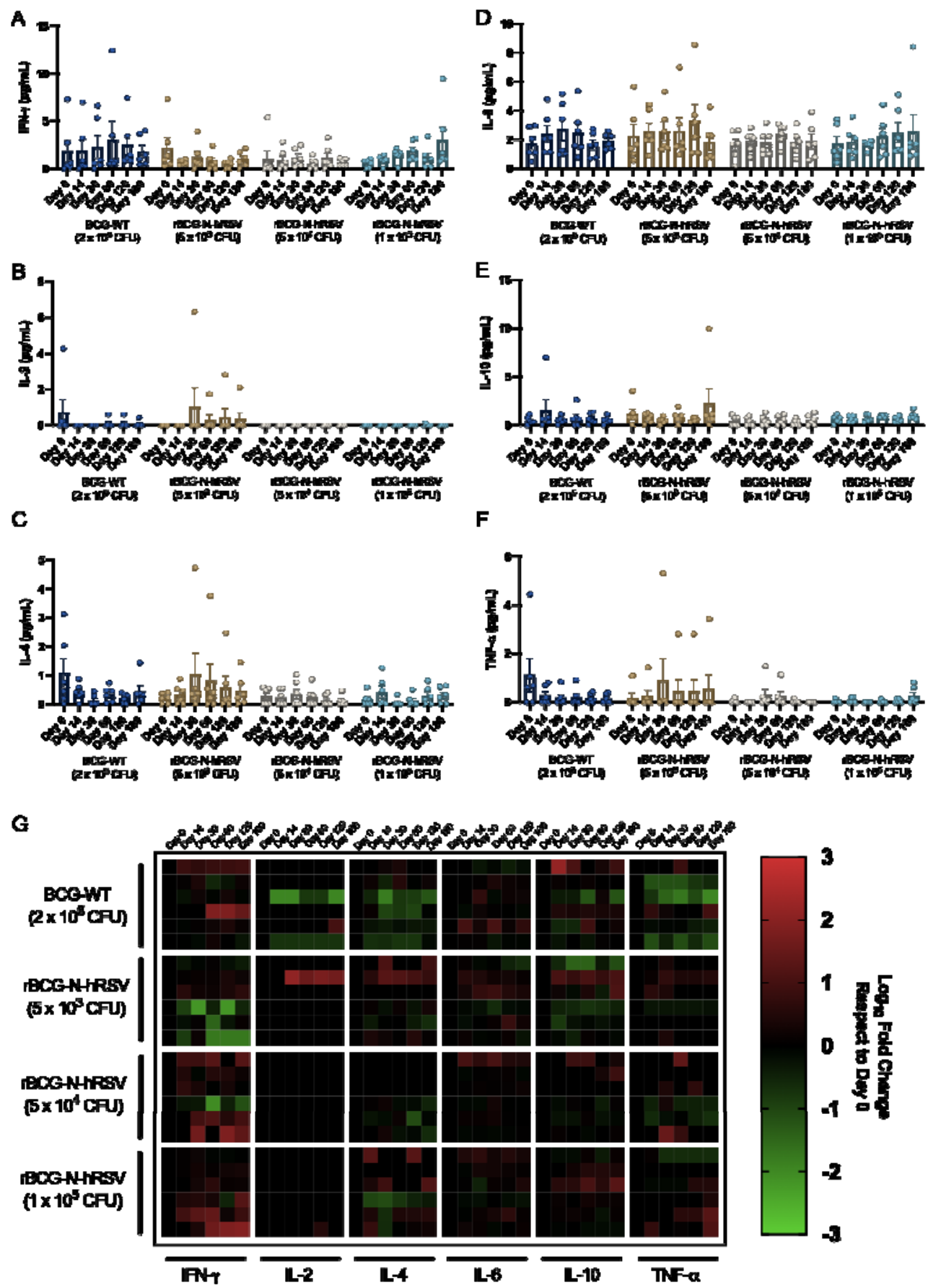

Figure 1. Immunization with rBCG-N-hRSV leads to a moderate systemic cytokine response. The concentration of (A) IFN- $\gamma$, (B) IL-2, (C) IL-4, (D) IL-6, (E) IL-10, and (F) TNF- $\alpha$ in sera samples are presented. Bars represent means, and error bars represent SEM. A two-way ANOVA for repeated measures with post-hoc Dunnet's test corrected for multiple comparisons against Day 0 was performed for the analysis of the data. (G) Heatmap of $\log _{10}$ fold change of the concentration of selected cytokines compared to Day 0. Each block of columns represents a particular cytokine, labeled below. Individual columns represent timepoints after immunization, specified above. Each block of rows represents a particular cohort of immunized study subjects, labeled left. Individual rows represent individual subjects. A color scale is depicted on the right. 


\section{Stimulation with N-hRSV}

A

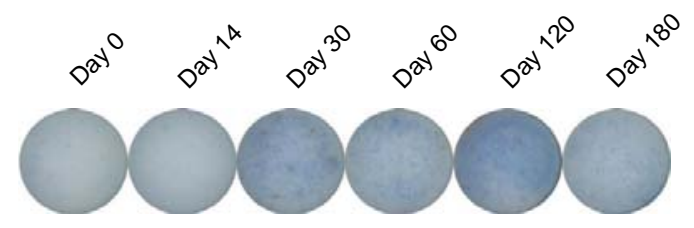

B

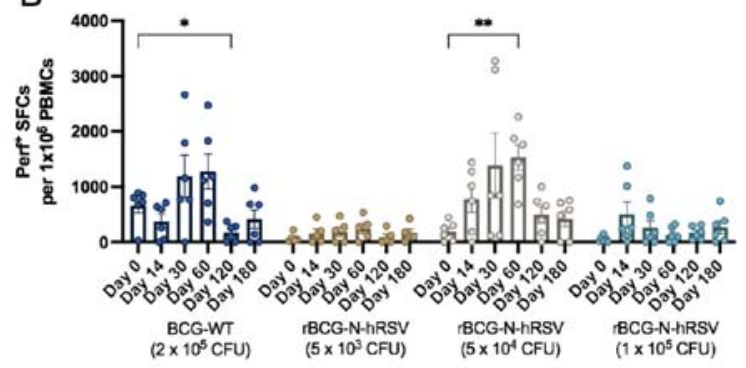

C

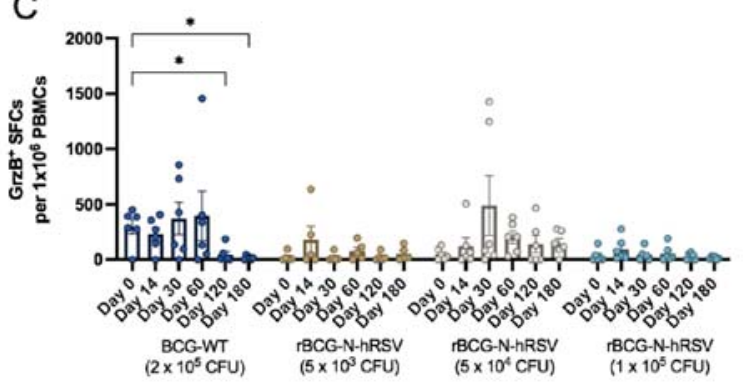

Stimulation with PPD

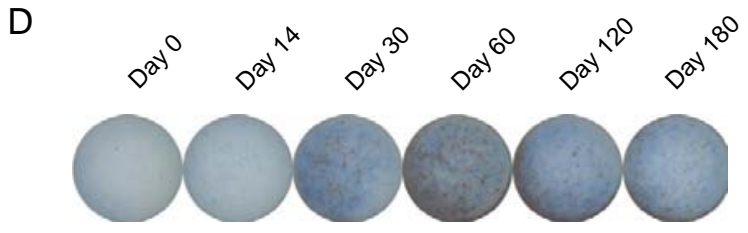

E

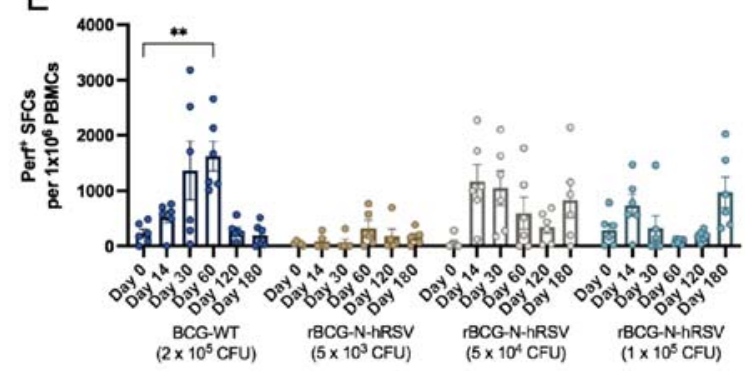

F

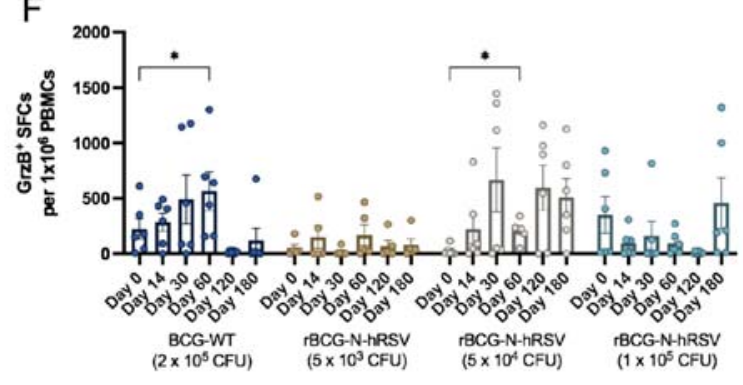

Figure 2. Stimulation with N-hRSV or PPD leads to enhanced Perforin and Granzyme B secretion by PBMCs from subjects immunized with $5 \times 10^{4}$ CFU of rBCG-N-hRSV. Representative pictures of ELISPOT wells in which PBMCs from subjects immunized with $5 \times 10^{4}$ CFU of rBCG-N-hRSV were stimulated with either (A) NhRSV or (C) PPD. Pictures are representative of subjects immunized with $5 \times 10^{4} \mathrm{CFU}$ of rBCG-N-hRSV. Blue spots are Perf ${ }^{+}$spot-forming cells (SFCs) and red spots are GrzB ${ }^{+}$SFCs. (B \& E) Perf ${ }^{+}$SFCs and $(\mathbf{C} \&$ F $)$ GrzB $^{+}$SFCs were counted after PBMCs were stimulated for 48 hours with either $1.25 \mu \mathrm{g} / \mathrm{mL}$ of N-hRSV (B-C) or $750 \mathrm{IU} / \mathrm{mL}$ of PPD (E-F). Bars represent the mean value of SFCs, and error bars represent the SEM. A two-way ANOVA for repeated measures with post-hoc Dunnet's test corrected for multiple comparisons relative to Day 0 was performed for the analysis of the data. $*=\mathrm{P}<0.05, \quad * *=\mathrm{P}<0.01$. 

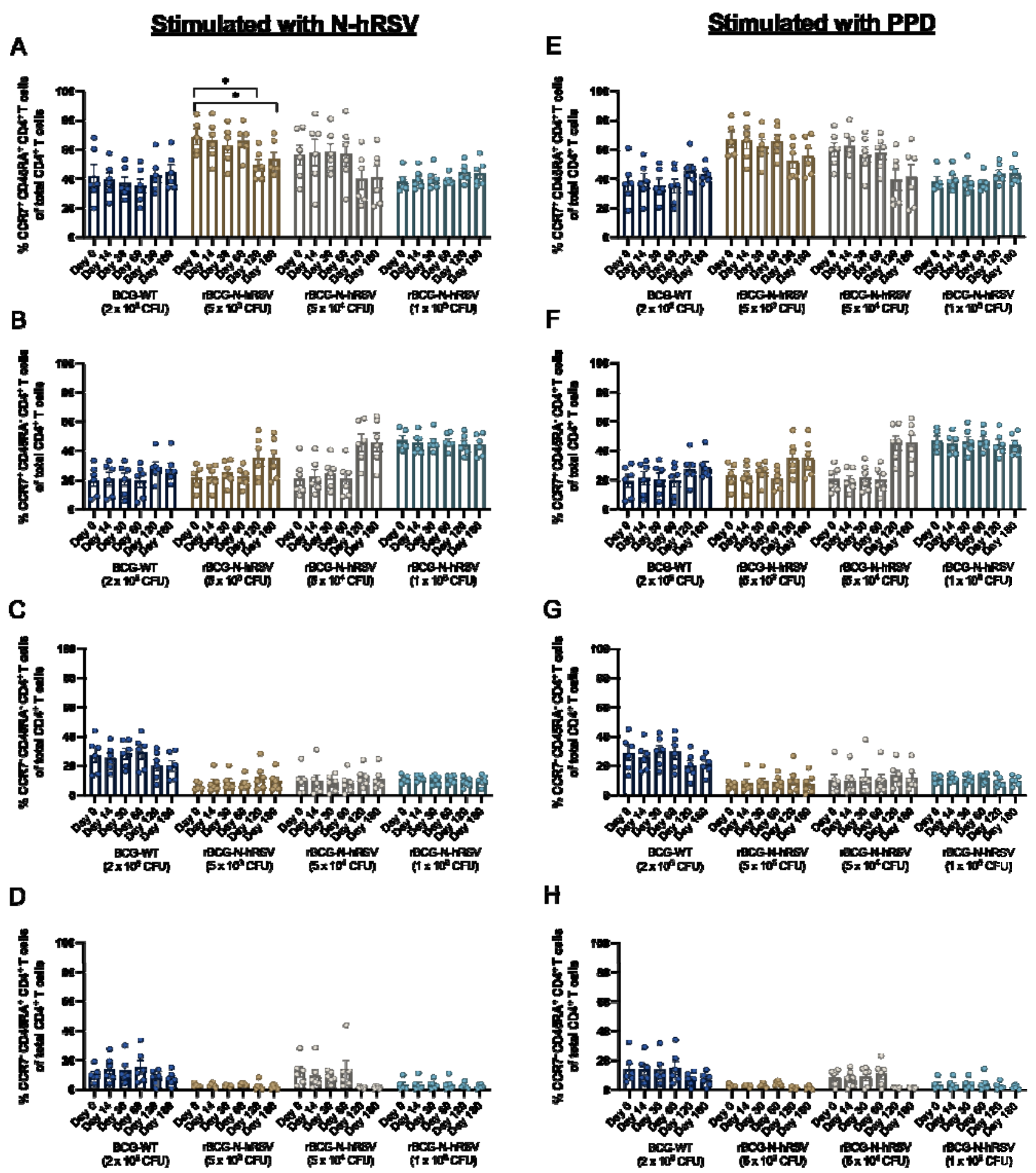

Figure 3. $\mathrm{CD4}^{+} \mathrm{T}$ cell memory subsets do not expand after a single immunization with rBCG-N-hRSV. T cell subsets defined by the expression of CCR7 and CD45RA were evaluated after stimulation of PBMCs with (A-D) NhRSV or (E-H) PPD. A two-way ANOVA for repeated measures with post-hoc Dunnet's test corrected for multiple comparisons compared to Day 0 was performed for the data analysis. $*=\mathrm{P}<0.05$. 
medRxiv preprint doi: https://doi.org/10.1101/2022.02.07.22270648; this version posted February 9, 2022. The copyright holder for this preprint (which was not certified by peer review) is the author/funder, who has granted medRxiv a license to display the preprint in perpetuity.

It is made available under a CC-BY-NC-ND 4.0 International license .
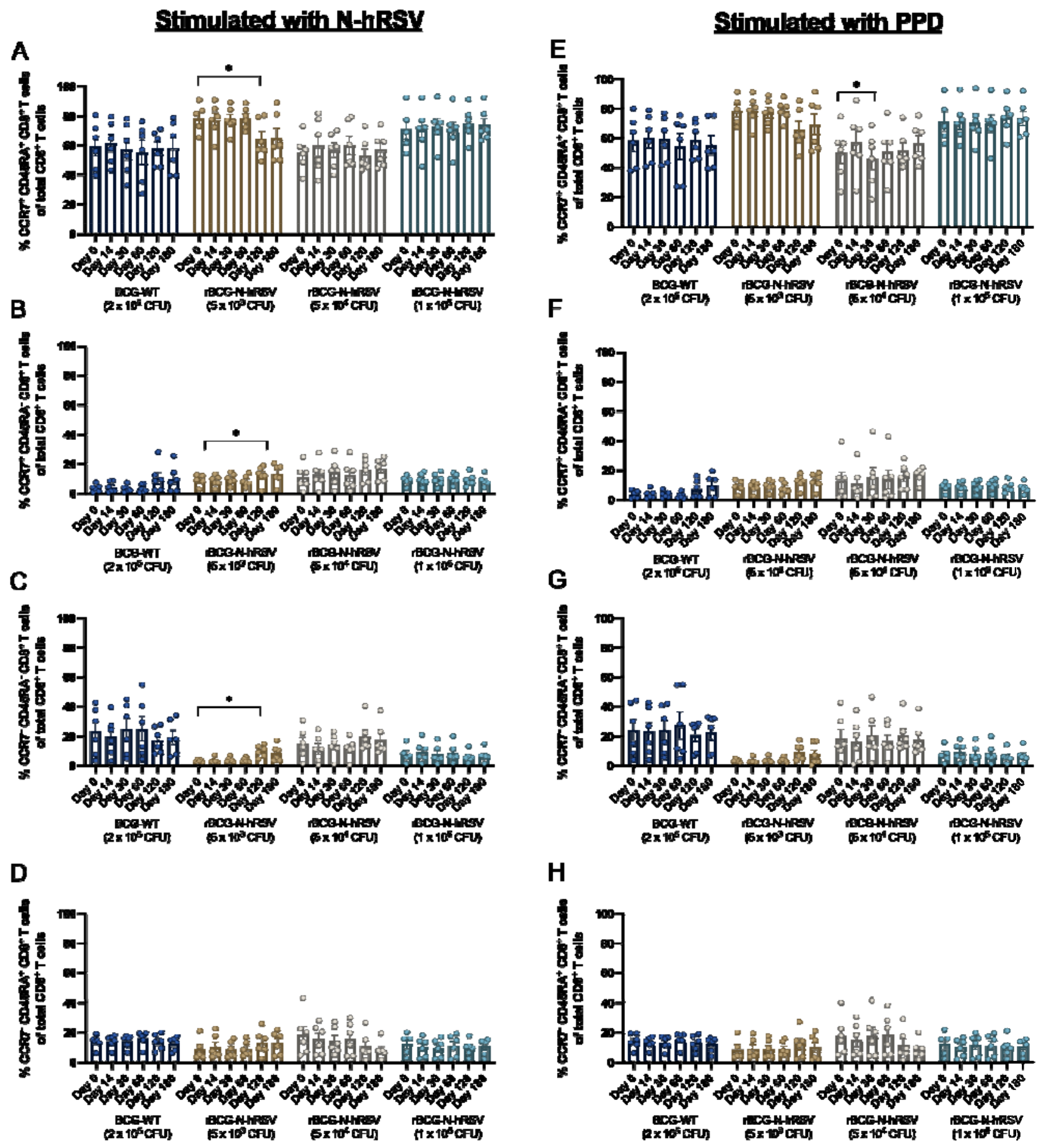

Figure 4. Quantification of $\mathrm{CDB}^{+} \mathrm{T}$ cell memory subsets after a single immunization with rBCG-N-hRSV. $\mathrm{T}$ cell subsets defined by the expression of CCR7 and CD45RA were evaluated after stimulation of PBMCs with (AD) N-hRSV or (E-H) PPD. Bars indicate means, while error bars represent SEM. A two-way ANOVA for repeated measures with post-hoc Dunnet's test corrected for multiple comparisons compared to Day 0 was performed for the data analysis. ${ }^{*}=\mathrm{P}<0.05$. 
A
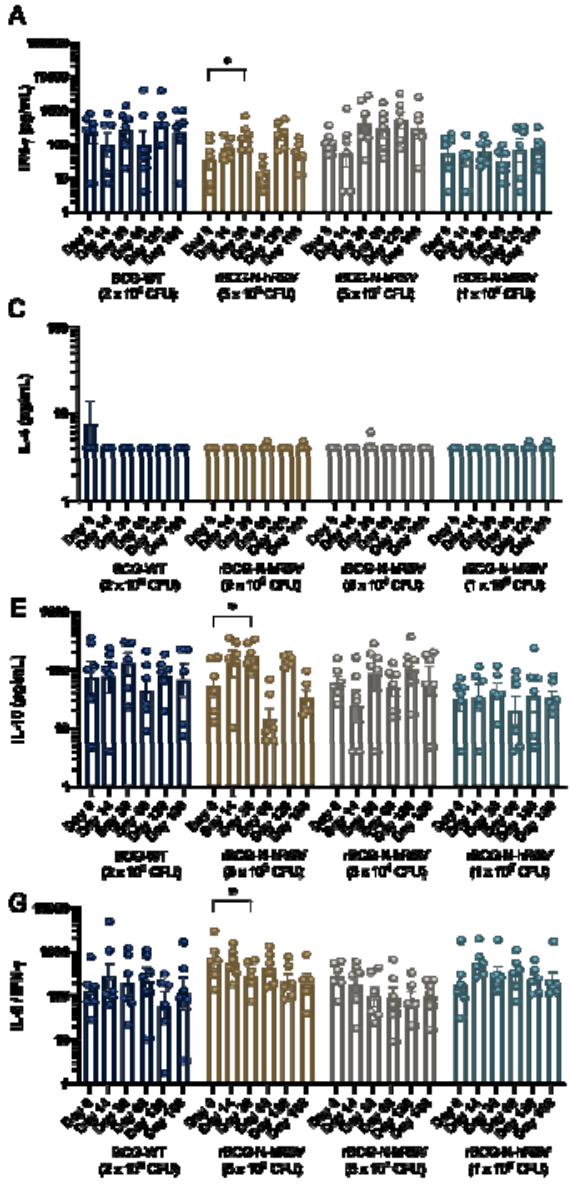

B
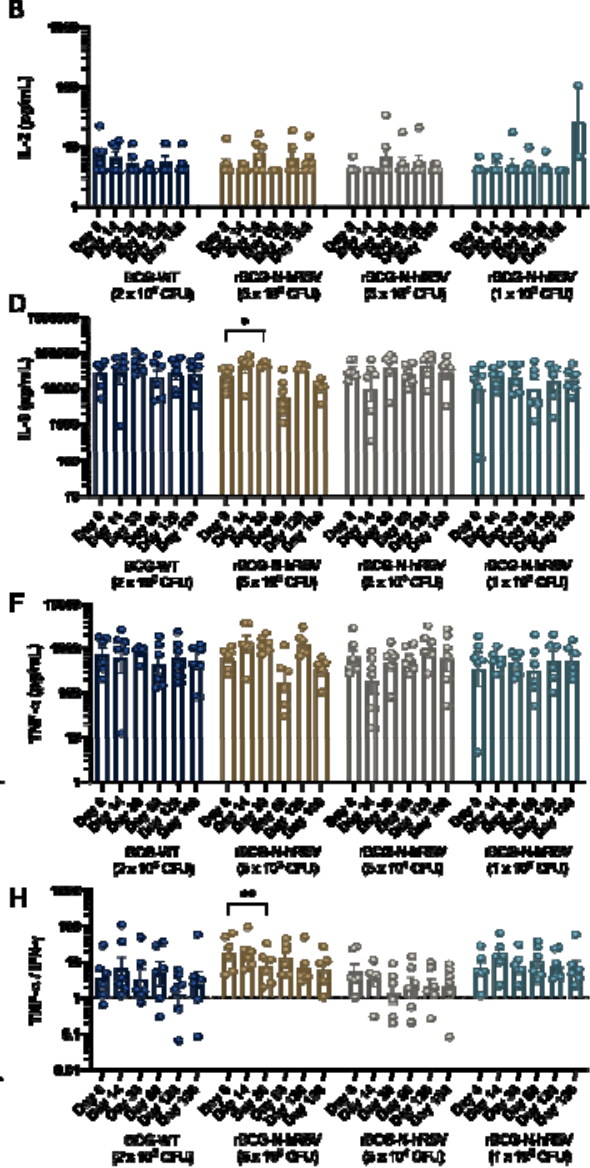

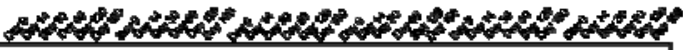

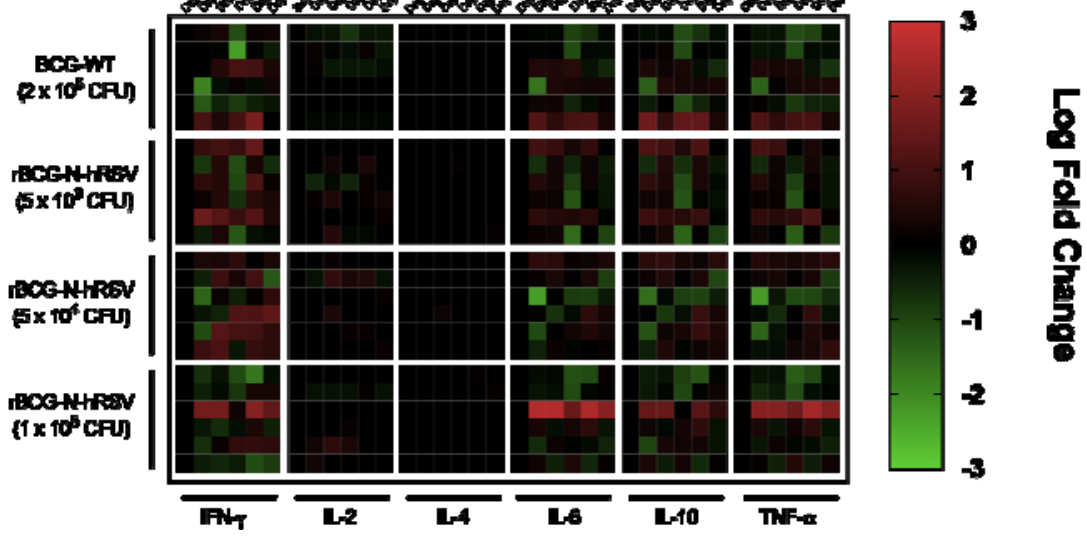

Figure 5. Stimulation with N-hRSV leads to IFN- $\gamma$ and IL-10 secretion by PBMCs from subjects immunized with $5 \times 10^{3}$ or $5 \times 10^{4}$ CFU of rBCG-N-hRSV. The concentration of (A) IFN- $\gamma$, (B) IL-2, (C) IL-4, (D) IL-6, (E) IL10, and (F) TNF- $\alpha$ in supernatants of PBMC cultures stimulated with $1.25 \mu \mathrm{g} / \mathrm{mL} \mathrm{N}$-hRSV are presented. Ratios between cytokines (G) IL-6 / IFN- $\gamma$ and (H) TNF- $\alpha$ / IFN- $\gamma$ were also calculated. Bars represent means and error bars represent SEM. A two-way ANOVA for repeated measures with post-hoc Dunnet's test corrected for multiple comparisons compared to Day 0 over the $\log _{10}$ was performed for the analysis of the data. $*=\mathrm{P}<0.05, * *=\mathrm{P}<0.01$. (I) Heatmap of $\log _{10}$ fold change of the concentration of selected cytokines compared to Day 0. Each block of columns represents a particular cytokine, labeled below. Individual columns represent timepoints after immunization, specified above. Each block of rows represents a particular cohort of immunized study subjects, labeled left. Individual rows represent individual subjects. A color scale is depicted on the right. 
A
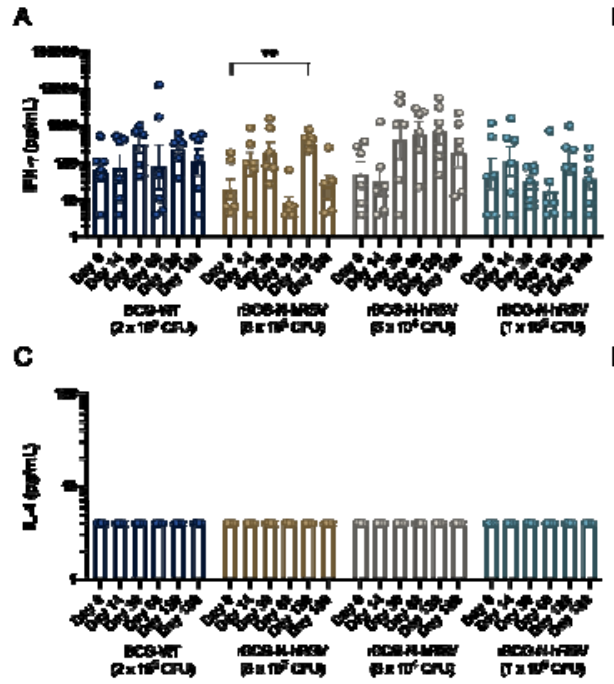

E

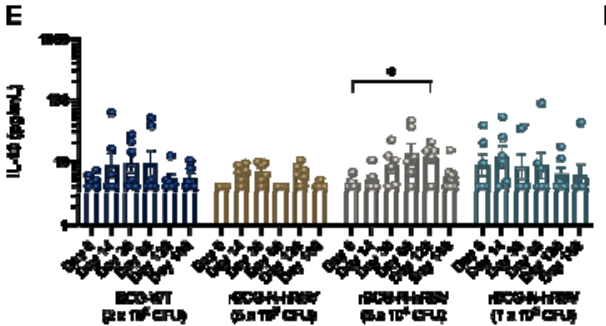

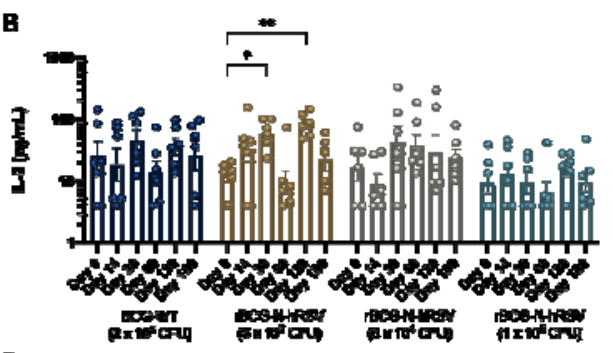
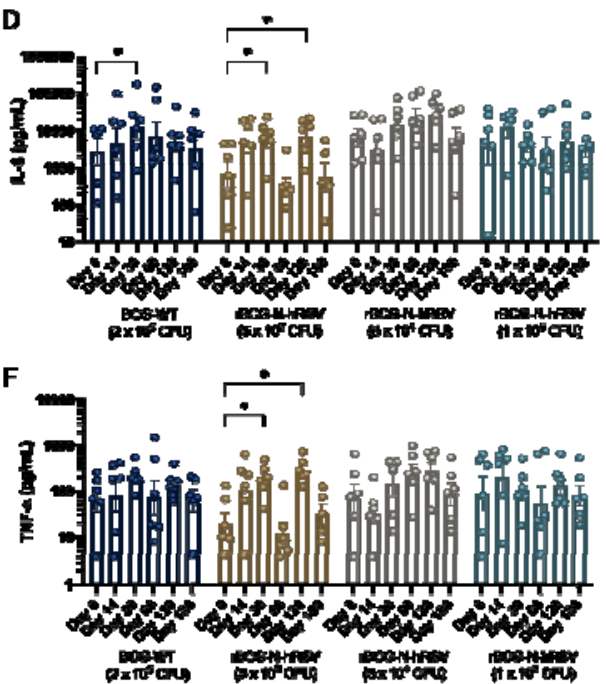

G

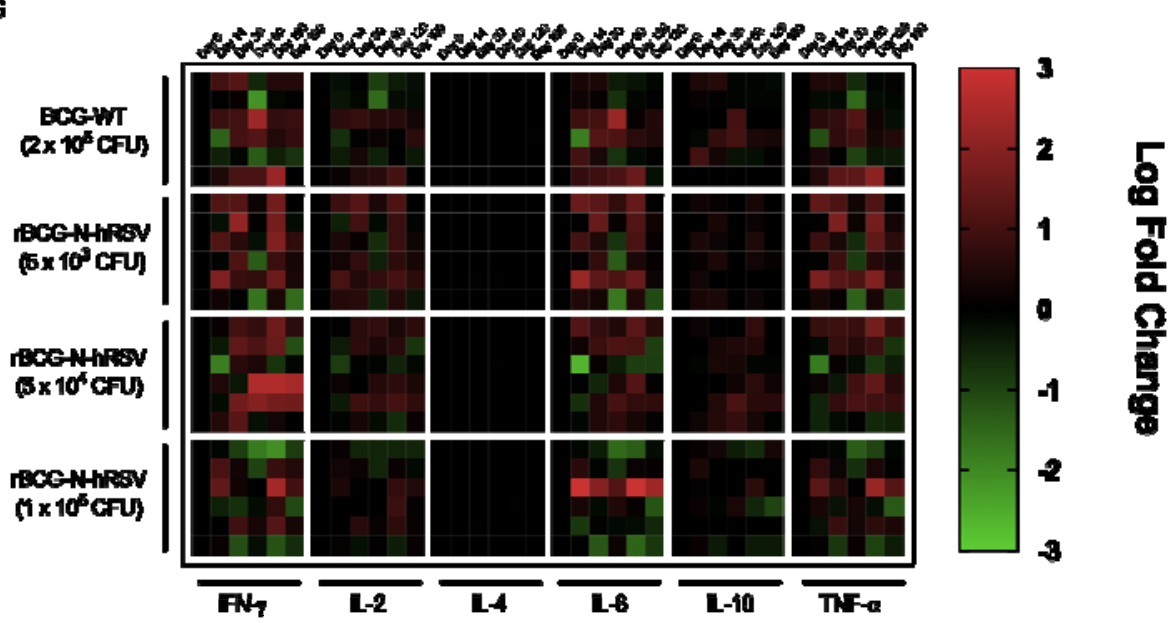

Figure 6. Stimulation with PPD leads to IFN- $\gamma$, TNF- $\alpha$, and IL-6 secretion by PBMCs subjects immunized with $5 \times 10^{3}$ or $5 \times 10^{4}$ CFU of rBCG-N-hRSV. The concentration of (A) IFN- $\gamma$, (B) IL-2, (C) IL-4, (D) IL-6, (E) IL10 , and (F) TNF- $\alpha$ in supernatants of PBMC cultures stimulated with $750 \mathrm{IU} / \mathrm{mL}$ PPD are presented. Bars represent means and error bars represent SEM. A two-way ANOVA for repeated measures with post-hoc Dunnet's test corrected for multiple comparisons compared to Day 0 over the $\log _{10}$ was performed for the analysis of the data. * $\mathrm{P}<0.05$, ** $=\mathrm{P}<0.01$. (G) Heatmap of $\log _{10}$ fold change of the concentration of selected cytokines compared to Day 0 . Each block of columns represents a particular cytokine, labeled below. Individual columns represent timepoints after immunization, specified above. Each block of rows represents a particular cohort of immunized study subjects, labeled left. Individual rows represent individual subjects. A color scale is depicted on the right. 
medRxiv preprint doi: https://doi.org/10.1101/2022.02.07.22270648; this version posted February 9, 2022. The copyright holder for this preprint (which was not certified by peer review) is the author/funder, who has granted medRxiv a license to display the preprint in perpetuity.

It is made available under a CC-BY-NC-ND 4.0 International license .

\section{Cig Binding to anti-N'hRSY antibodies}

A
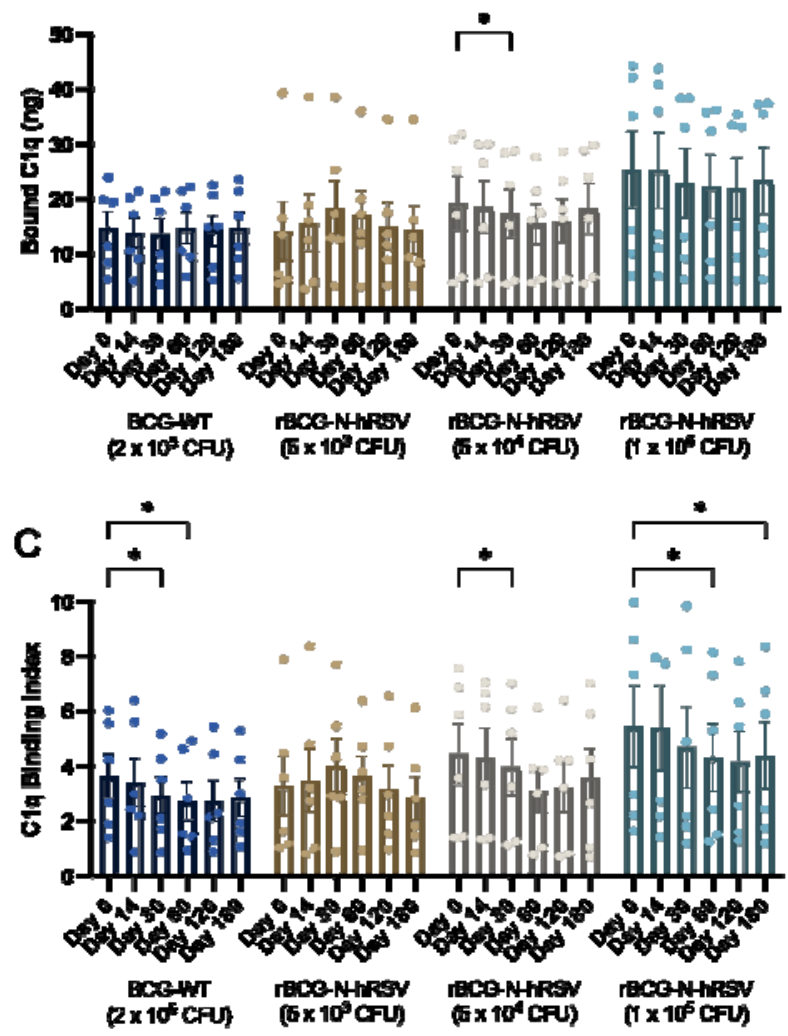

\section{Clg Binding to antiPPD antibodies}

B
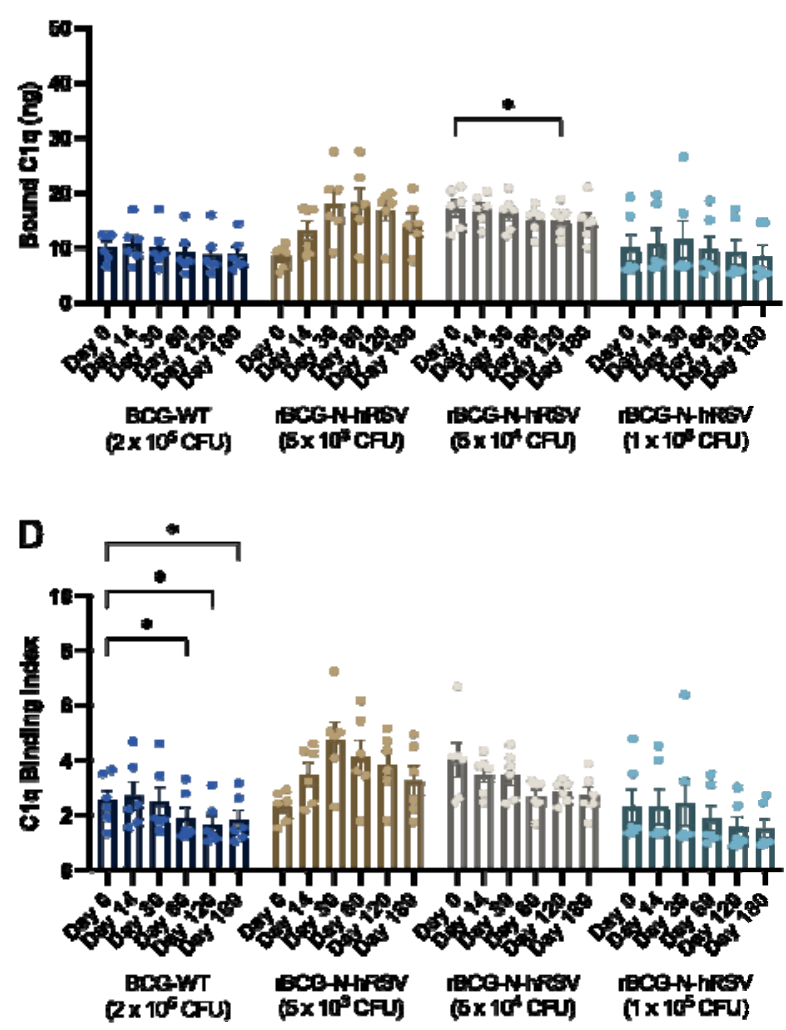

Figure 7. Reduced C1q binding by virus- and mycobacteria-specific antibodies induced by rBCG-N-hRSV. Total C1q binding is shown for (A) total anti-N-hRSV antibodies and (B) total anti-PPD antibodies. A C1q Binding Index was calculated by dividing total bound C1q by the $\log _{10}$ of total IgG against (C) N-hRSV or (D) PPD. Bars indicate means, while error bars represent SEM. A two-way ANOVA for repeated measures with post-hoc Dunnet's test corrected for multiple comparisons compared to Day 0 was performed for the analysis of the data. $*=\mathrm{P}<0.05$. 
A
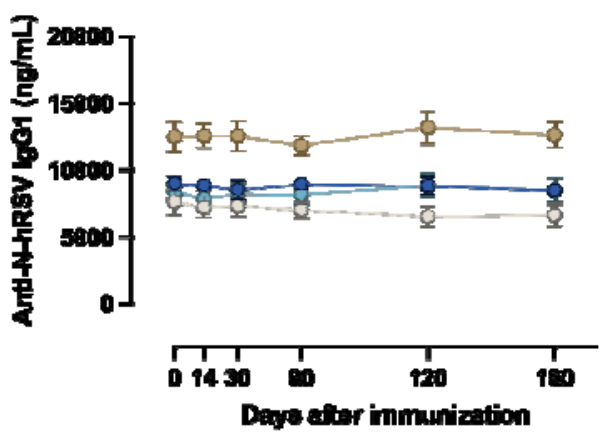

C

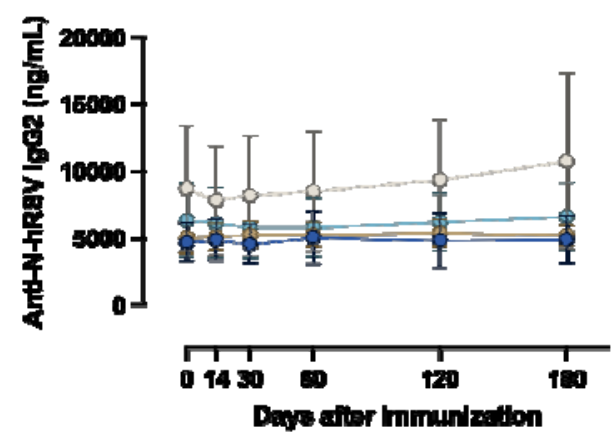

B
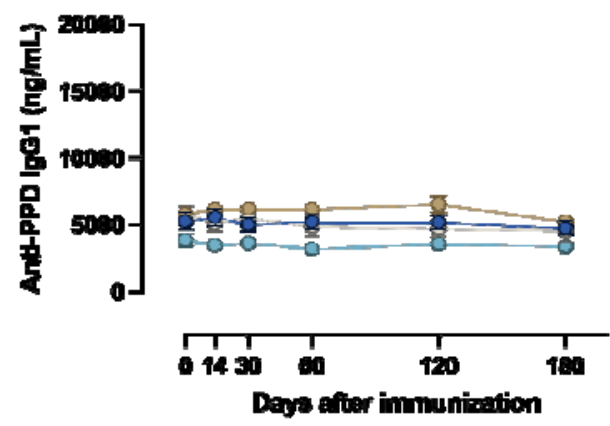

D
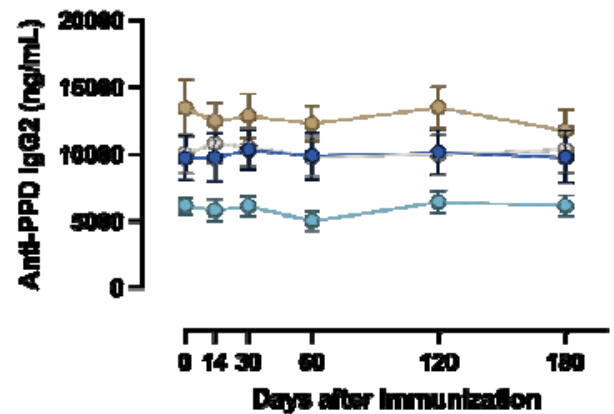

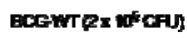

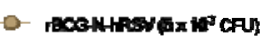

- NCONHFEN

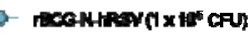

Figure 8. rBCG-N-hRSV immunization induces equivalent IgG subclass secretion. (A-B) IgG1 and (C-D) IgG2 antibody titers were measured via ELISA. Depicted are (A \& C) anti-N-hRSV and (B \& D) anti-PPD antibody concentrations over time. Dots represent mean titers, while error bars represent SEM. A two-way ANOVA for repeated measures with post-hoc Dunnet's test corrected for multiple comparisons compared to Day 0 was performed for the analysis of the data. 